Article

\title{
Green Process for Industrial Waste Transformation into Super-Oxidizing Materials Named Alkali Metal Ferrates (VI)
}

\author{
Ndue Kanari ${ }^{1}{ }^{1 *}\left(\mathbb{D}\right.$, Etleva Ostrosi ${ }^{2}$, Cécile Diliberto ${ }^{3}$, Inna Filippova ${ }^{1}$, Seit Shallari ${ }^{4}$, \\ Eric Allain ${ }^{1}$, Frederic Diot ${ }^{1}$, Fabrice Patisson ${ }^{5}(\mathbb{D})$ and Jacques Yvon ${ }^{1}$ \\ 1 GeoRessources Laboratory, UMR 7359 CNRS, CREGU, Université de Lorraine, 2, rue du doyen Roubault, \\ BP 10162, 54505 Vandoeuvre-lès-Nancy, France; inna.filippova@univ-lorraine.fr (I.F.); \\ ericgallain@gmail.com (E.A.); frederic.diot@univ-lorraine.fr (F.D.); jacques.yvon@univ-lorraine.fr (J.Y.) \\ 2 Ville de Montréal, Direction de l'environnement, Division de la Planification et du Suivi Environnemental, \\ 801, rue Brennan, Montréal, QC H3C 0G4, Canada; etlevao@yahoo.com \\ 3 Institut Jean Lamour, UMR 7198 CNRS, Université de Lorraine, Equipe 'Matériaux pour le Génie Civil', \\ IUTNB, BP 90137, 54600 Villers-lès-Nancy, France; cecile.diliberto@univ-lorraine.fr \\ 4 Agricultural University of Tirana, Faculty of Agriculture and Environment, 1029 Tirana, Albania; \\ seitshallari@gmail.com \\ 5 Institut Jean Lamour, UMR 7198 CNRS, Labex DAMAS, Université de Lorraine, Campus Artem, \\ 2 allée André Guinier, BP 50840, 54011 Nancy, France; fabrice.patisson@univ-lorraine.fr \\ * Correspondence: ndue.kanari@univ-lorraine.fr; Tel.: +33-372-744-530
}

Received: 29 May 2019; Accepted: 17 June 2019; Published: 19 June 2019

\begin{abstract}
The investigation presented here features the design of a cleaner and greener chemical process for the conversion of industrial wastes into super-oxidizing materials. The waste of interest is the iron sulfate heptahydrate $\left(\mathrm{FeSO}_{4} \cdot 7 \mathrm{H}_{2} \mathrm{O}\right)$ mainly generated through the sulfate route used for titanium dioxide industrial production. The products of this transformation process are alkali ferrates $\left(\mathrm{A}_{2} \mathrm{FeO}_{4}, \mathrm{~A}=\mathrm{Na}, \mathrm{K}\right)$ containing iron in its hexavalent state and considered as powerful oxidants characterized by properties useful for cleaning waters, wastewaters, and industrial effluents. The proposed process includes two steps: (i) The first step consisting of the pre-mixing of two solids $\left(\mathrm{AOH}\right.$ with $\left.\mathrm{FeSO}_{4} \cdot \mathrm{xH}_{2} \mathrm{O}\right)$ in a rotary reactor allowing the coating of iron sulfate in the alkali hydroxides through solid-solid reactions; and (ii) the second step involves the synthesis of alkali ferrates in a fluidized bed by oxidation of the single solid obtained in the first step in diluted chlorine. The chemical synthesis of alkali ferrates can be carried out within a timeframe of a few minutes. The usage of a fluidized bed enhanced the energy and mass transfer allowing a quasi-complete control of the ferrate synthesis process. The alkali ferrate synthesis process described here possesses many characteristics aligned with the principles of the "green chemistry".
\end{abstract}

Keywords: industrial waste; alkali ferrates; super-oxidizing materials; fluidized bed; green process

\section{Introduction}

Iron compounds are abundant in most nonferrous metal deposits where these metals often represent a small fraction. Although part of the ferrous components are separated during mining and primary mineral processing, a large part of iron goes through the extractive processes of these metals. Further, the iron is sometimes present in the natural mineral bodies (e.g., $\mathrm{FeTiO}_{3}, \mathrm{CuFeS}_{2}$, $\left.(\mathrm{Ni}, \mathrm{Fe})_{9} \mathrm{~S}_{8}\right)$ of target metals that can be separated during the primary metal extraction. Therefore, considerable amounts of iron bearing co-products and wastes are inevitably generated from both hydro- and pyro-metallurgical operations on such raw materials. 
One typical industrial example of generation of iron-containing waste is the extraction of titanium oxide $\left(\mathrm{TiO}_{2}\right)$ from its bearing materials such as ilmenite, rutile, anatase, and slags. As described previously [1], "chloride" and "sulfate" routes are processes currently used for $\mathrm{TiO}_{2}$ production. The sulfate process, using ilmenite $\left(\mathrm{FeTiO}_{3}\right)$ as a raw material, can lead to the generation of amounts of iron sulfate ( $\mathrm{FeSO}_{4} \cdot 7 \mathrm{H}_{2} \mathrm{O}$ - melanterite) as high as 6 tons of $\mathrm{FeSO}_{4} \cdot 7 \mathrm{H}_{2} \mathrm{O}$ per ton of produced $\mathrm{TiO}_{2}$ [2], which is a real environmental drawback for the $\mathrm{TiO}_{2}$ industry. By 1993, all countries producing $\mathrm{TiO}_{2}$ through the sulfate process had to comply with the European directive [3] in order to avoid dumping industrial waste (such as melanterite) into the seawater. In the perspective of a circular economy and sustainable development, the ideal scenario should be to consider these wastes (e.g., iron sulfate) as an input for new chemicals and material synthesis, which are intrinsically non-hazardous, thus excluding the notion of undesirable by-product. Few recent investigations [4-7] address the usage of melanterite in various application and its treatment, such as for synthesizing slow-release fertilizers [5], cation-substituted $\mathrm{LiFePO}_{4}$ [6], and for $\mathrm{Fe}_{3} \mathrm{O}_{4}$ production through reductive decomposition using pyrite [7].

As a continuation of our previous research investigations [2,8-10], the present work aims at transforming industrial iron sulfate into alkali metal ferrates $\left(\mathrm{A}_{2} \mathrm{FeO}_{4}, \mathrm{~A}=\mathrm{Na}, \mathrm{K}\right)$ considered as useful materials in different fields. One may note that the denomination "ferrate" is generally attributed to compounds containing iron at an oxidation state higher than $\mathrm{Fe}(\mathrm{III})$ and the ferrates(VI) seem to be the best known and most studied [2]. In an aqueous solution, the ferrate ion $\left(\mathrm{FeO}_{4}{ }^{2-}\right)$ is reduced, generating both $\mathrm{Fe}(\mathrm{OH})_{3}$ and nascent oxygen (Equation (1)). As summarized early [2], ferrates are used for water treatment due to their powerful oxidizing capacity $\left(\mathrm{E}\left(\mathrm{FeO}_{4}{ }^{2-} / \mathrm{Fe}^{3+}=2.2 \mathrm{~V}\right)\right.$ ) (oxidation of organic and mineral materials, bactericide agent) and because of the flocculating property of the evolved $\mathrm{Fe}(\mathrm{OH})_{3}$. The ferrates can replace chlorine in the pre-oxidation stage of water and can partially be used as a substitute of the iron and aluminum salts used as coagulating and flocculating agents. Furthermore, the decomposition of alkali ferrates generates basic medium favorable for the precipitation of heavy metals. These properties existing together in one single compound make ferrates an ongoing material particularly interesting for water treatment and effluent cleaning. Moreover, the oxidation products (iron oxy/hydroxides) (Equation (1)) are inoffensive to the environment.

$$
2 \mathrm{FeO}_{4}{ }^{2-}+5 \mathrm{H}_{2} \mathrm{O} \rightarrow 2 \mathrm{Fe}(\mathrm{OH})_{3}+4 \mathrm{OH}^{-}+3 \mathrm{O}^{\bullet}
$$

The research works performed by Fremy [11-13] are frequently cited in the literature as the first ones to scientifically reveal the existence of iron in a hexavalent state and to effectively achieve ferrates synthesis. Since then, the preparation methods, developed mostly on a laboratory scale, have made little progress, and can be classified into three groups:

- The high temperature route consisting of heating and/or melting various iron oxides bearing materials under high concentration of alkali substances and oxygen flow [14-16]. These synthesis methods, performed at temperatures as high as $800{ }^{\circ} \mathrm{C}$, seem to be mostly ineffective since the $\mathrm{Fe}(\mathrm{VI})$ is not stable at temperatures higher than $200^{\circ} \mathrm{C}$. Most probably, the $\mathrm{Fe}(\mathrm{VI})$ resulted from the dismutation of synthetized $\mathrm{Fe}(\mathrm{IV})$ and/or $\mathrm{Fe}(\mathrm{V})$ during the manipulation with the synthesis product.

- The wet/humid oxidation of Fe(III) salts bearing solutions, under strong alkaline conditions, using hypochlorite or chlorine as oxidant. This method is the most used since the 1950s [17-20]. One of the drawbacks is that the wet method used pure chemicals and required many operations for $\mathrm{Fe}(\mathrm{VI})$ preparation and separation, making it very costly. Moreover, the water reacts with ferrate (Equation (1)) leading to its reduction into Fe(III).

- The electrochemical method [21-23], allowing the oxidation of anode (iron or its alloys) by operating mainly in concentrated $\mathrm{NaOH}$ and/or $\mathrm{KOH}$ solutions. However, the decomposition of $\mathrm{Fe}(\mathrm{VI})$ by water, low current efficiency, and anode passivation are some of the concerns for this route.

Synthesis of alkali ferrates (AF) by gas-solid reactions performed in a rotary reactor using chlorine as an oxidant showed that synthesis was achieved without external heat supply [2,8-10]. However, 
it was observed that the synthesis reactions were highly exothermic leading to a temperature rise in the reaction zone above $150^{\circ} \mathrm{C}$, when only $10 \mathrm{~g}$ of solids were used for the potassium and/or sodium ferrate synthesis. Experimental results indicated that the heat generation provoked the sample agglomeration and dramatically decreased the $\mathrm{Fe}(\mathrm{VI})$ efficiency of the synthesis process. The temperature increase phenomena became a real "obstacle" when higher amounts $(100 \mathrm{~g})$ of solids were used for the AF synthesis, although the reactor was cooled. Further, the kinetic of Na-ferrate synthesis is expected to be low compared with that of potassium ferrate [2]. In other words, it was concluded that the synthesis of alkali ferrates in a rotary reactor would not be considered as an appropriate route for an eventual AF large-scale production.

In this context, the goal of this research work is threefold: (i) Use the industrial iron sulfate as raw material for the AF synthesis; (ii) develop an appropriate process for AF preparation at room temperature; (iii) optimize the process by data analysis of various parameters affecting the efficiency of $\mathrm{Fe}(\mathrm{II}, \mathrm{III})$ conversion into $\mathrm{Fe}(\mathrm{VI})$. The AF synthesis (mostly sodium ferrate preparation) is achieved in fluidized bed (FB) which can be considered as an appropriate reactor for handling processes that require high energy and mass transfers. It should be noted that the alkali metal ferrates (VI) manufacturing process, as developed in this work, is unique in its field.

\section{Materials and Methods}

Industrial ferrous sulfate (mainly monohydrate) is used for the synthesis of alkali ferrates. An examination by scanning electron microscope (Hitachi Ltd., Tokyo, Japan) coupled with energy dispersive spectrometry (Kevex Corp., Foster, CA, USA) (SEM-EDS), X-ray diffraction (XRD), chemical analyses, and Mössbauer spectroscopy (MS) suggested that the sample is free of heavy metals and that the quasi-totality of iron is in a bivalent state as $\mathrm{FeSO}_{4} \cdot \mathrm{H}_{2} \mathrm{O}$. Another sample of ferrous sulfate heptahydrate is also used after dehydration in an oven at about $150{ }^{\circ} \mathrm{C}$ leading to the formation of $\mathrm{FeSO}_{4} \cdot \mathrm{H}_{2} \mathrm{O}$ and $\mathrm{FeSO}_{4} \cdot \mathrm{OH}$ as the main iron-bearing phases. Commercial sodium hydroxide is used as pellets of $2 \mathrm{~mm}$ and pearls of about $1 \mathrm{~mm}$. The oxidizing agent (chlorine) and diluting gas (nitrogen) were of high purity, whilst the air was supplied by a compressor.

The flowchart summarizing the features of the experimental protocol established for the synthesis of alkali ferrates is schematized in Figure 1. Accordingly, the synthesis process consisted of two main steps. The first step consists of a premixing of mostly $\mathrm{FeSO}_{4} \cdot \mathrm{H}_{2} \mathrm{O}$ and/or $\mathrm{FeSO}_{4} \cdot \mathrm{OH}$ with $\mathrm{NaOH}$ resulting in a single solid. This step is realized by using the experimental setup represented in Figure 2. The parameters studied for the solid premixing step are related to physical characteristics of iron sulfate and $\mathrm{NaOH}$ feed, their amounts, as well as the premixing time.

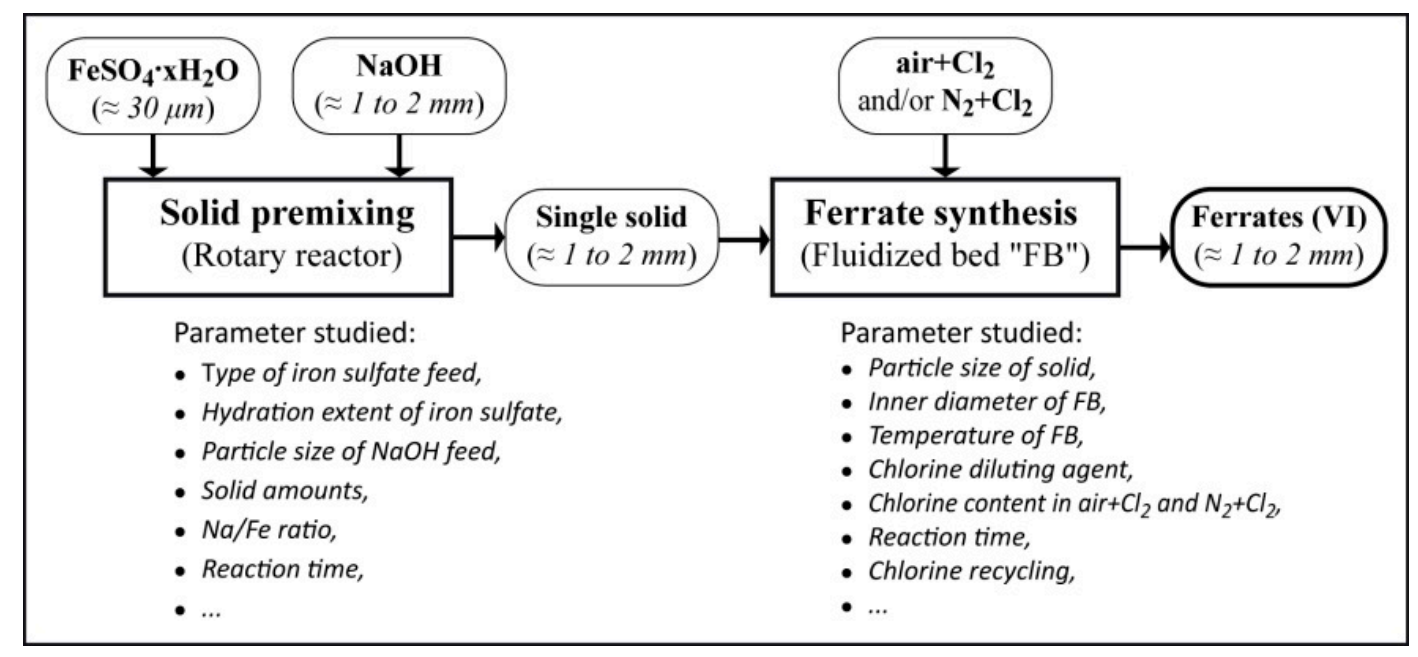

Figure 1. Schematic representation of the experimental procedure applied for the ferrates(VI) synthesis through a two-step process. 


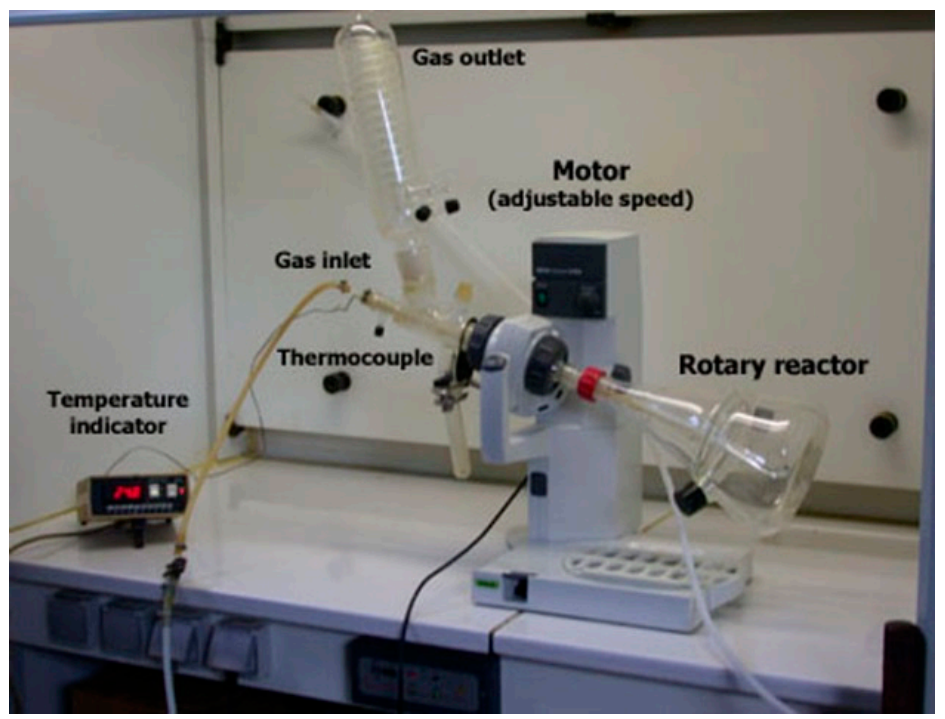

Figure 2. Apparatus assembly with a baffled reactor used for mixing iron sulfate with sodium hydroxide.

The second step of the synthesis process (Figure 1) consists of the reaction of the granulated and single solid, prepared in step 1 , with chlorine diluted in air and/or $\mathrm{N}_{2}$ leading to the sodium ferrate preparation. A fluidized bed reactor equipped with a temperature-regulated water system is used for the experimental tests of alkali ferrate synthesis. A second fluidized bed is added in series for recycling the unreacted oxidant (chlorine) during AF synthesis taking place in the first fluidized bed. Several experimental parameters related to the ferrate synthesis step (particle size of solid, temperature, chlorine content, reaction time) were investigated. Other details of the experimental procedure will be introduced when describing the experimental results for both steps.

Solid synthesis products are subjected to visible microscopy, SEM-EDS, and XRD to examine the structure and the composition of the solid reaction products. The procedure of these characterization techniques is given in a recently published material [24].

Mössbauer spectroscopy was used to seek information about the oxidation state of iron as well as to evaluate the $\mathrm{Fe}(\mathrm{VI})$ content in the synthesis product. Details about this analysis method were given earlier by Jeannot et al. [25]. However, this method of examination is time consuming, i.e., the acquisition of a Mössbauer spectrum may take up to $24 \mathrm{~h}$. In this context, a chemical analysis method is performed to quickly determine the $\mathrm{Fe}(\mathrm{VI})$ synthesis efficiency of the ferrate synthesis trials. This method is based on the chemical reaction of $\mathrm{Fe}(\mathrm{VI})$ with an excess of ferrous sulfate solution; then, the excess of $\mathrm{Fe}(\mathrm{II})$ is titrated with potassium bichromate.

\section{Results and Discussion}

\subsection{Concept of the Vibrating Fluidized Bed}

The fluidized bed technique is very attractive for different processes related to gas-solid reactions and for its easy extrapolation. However, a fluidized bed is not suitable for solids with important differences in particles sizes (or density), as it is the case of $\mathrm{NaOH}$ and iron sulfate. As a reminder, the mean particle sizes of $\mathrm{NaOH}$, found in market, were about 1, 2, and $5 \mathrm{~mm}$ and that of $\mathrm{FeSO}_{4} \cdot \mathrm{H}_{2} \mathrm{O}$ is less than $100 \mu \mathrm{m}$. A conventional fluidization of $\mathrm{NaOH}$ and $\mathrm{FeSO}_{4} \cdot \mathrm{H}_{2} \mathrm{O}$ (for a given fluidization velocity) allows a heterogeneous distribution of the solids in the reactor. It was suggested that the vibrating fluidized bed would be a solution for the homogeneous fluidization of $\mathrm{NaOH}$ and iron sulfate. The distribution of particles in the bed through the respective conditions of the fluidization alone, vibration alone, and fluidization coupled with vibration are schematized in Figure 3. The choice of the optimal fluidization velocity of the reactive gases for the iron sulfate creates the distribution situation described in Figure 3a. Thus, iron sulfate is fluidized when the $\mathrm{NaOH}$ pearls creates a packed 
bed at the bottom of the reactor. If the bed is only vibrated (Figure 3b), the pearls of $\mathrm{NaOH}$ move towards the top, while the iron sulfate accumulates at the bottom of the reactor. Meanwhile, the use of blow and vibration leads to an almost homogenous 'fluidization' of both solids $\left(\mathrm{FeSO}_{4}\right.$ and $\left.\mathrm{NaOH}\right)$ as described in Figure 3c. However, it seems that the vibrating fluidized bed is difficult to control on an industrial scale production, especially for delicate processes such as ferrate synthesis.

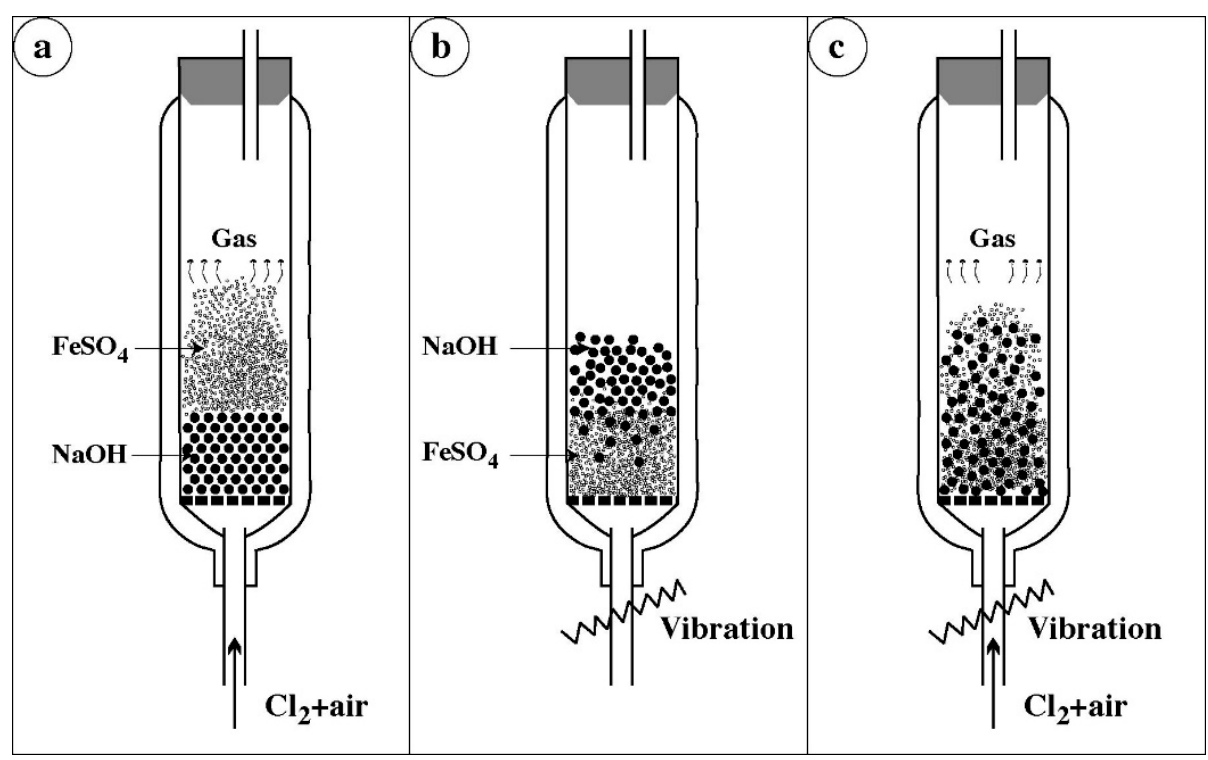

Figure 3. Schematic particles distribution of solids in a vibrated fluidized bed: (a) optimal gas fluidization velocity for iron sulfate; (b) only vibration of fluidized bed; (c) simultaneous blowing and vibration of fluidized bed.

\subsection{Idea of Premixing of Solids Prior to Fluidization}

The overall reaction of the sodium ferrate synthesis can be described by Equation (2), although the exact formula of this compound seems to be still undefined. It was already confirmed experimentally that the synthesis of Na-ferrate via Equation (2) is exothermic. The possible "two by two" reactions of the three substances $\left(\mathrm{FeSO}_{4} \cdot \mathrm{H}_{2} \mathrm{O}, \mathrm{Cl}_{2}\right.$, and $\left.\mathrm{NaOH}\right)$ could be represented by Equations (3)-(5). Iron sulfate monohydrate does not react with chlorine at room temperature. Recent experience in the field of gaseous chlorine reactivity with iron compounds showed that the oxidation of $\mathrm{Fe}(\mathrm{II})$ of wüstite (FeO) into $\mathrm{Fe}(\mathrm{III})$ takes place at temperatures higher than $200{ }^{\circ} \mathrm{C}$ [26]. Chlorine in the presence of oxygen can oxidize $\mathrm{Cr}(\mathrm{III})$ into $\mathrm{Cr}(\mathrm{VI})$, generating chromium oxychloride [27-29].

As could be expected, the reaction of chlorine with $\mathrm{NaOH}$ produces $\mathrm{NaCl}$ as a final reaction product involving heat with $\Delta \mathrm{H}=-128 \mathrm{~kJ} / \mathrm{mol} \mathrm{NaOH}$ [30]. The most interesting reaction to be considered is that of iron sulfate with sodium hydroxide (Equation (5)) resulting in the formation of $\mathrm{Na}_{2} \mathrm{SO}_{4}$. The sodium sulfate is also an unavoidable product of the Na-ferrate synthesis (Equation (2)). Consequently, it was suggested to react iron sulfate with $\mathrm{NaOH}$, allowing them to form a single solid (mixture of $\mathrm{Fe}(\mathrm{OH})_{2}$ and $\mathrm{Na}_{2} \mathrm{SO}_{4}$ ), which would be suitable for the subsequent fluidization in the FB.

The following paragraphs will describe the experimental results of the solid premixing concept.

$$
\begin{gathered}
\mathrm{FeSO}_{4} \cdot \mathrm{H}_{2} \mathrm{O}+2 \mathrm{Cl}_{2}+8 \mathrm{NaOH} \rightarrow \mathrm{Na}_{2} \mathrm{FeO}_{4}+\mathrm{Na}_{2} \mathrm{SO}_{4}+4 \mathrm{NaCl}+5 \mathrm{H}_{2} \mathrm{O} \\
\mathrm{FeSO}_{4} \cdot \mathrm{H}_{2} \mathrm{O}+\mathrm{Cl}_{2} \rightarrow \mathrm{No} \text { evident reaction at room temperature } \\
2 \mathrm{NaOH}+\mathrm{Cl}_{2} \rightarrow 2 \mathrm{NaCl}+\mathrm{H}_{2} \mathrm{O}+0.5 \mathrm{O}_{2} \\
\mathrm{FeSO}_{4} \cdot \mathrm{H}_{2} \mathrm{O}+2 \mathrm{NaOH} \rightarrow \mathrm{Fe}(\mathrm{OH})_{2}+\mathrm{Na}_{2} \mathrm{SO}_{4}+\mathrm{H}_{2} \mathrm{O}
\end{gathered}
$$




\subsection{Premixing of $\mathrm{NaOH}$ Pellets $(2 \mathrm{~mm})$ with Iron Sulfate}

Sodium hydroxide conditioned as 2-mm pellets was used for the experimental tests. Iron sulfate monohydrate was chosen as iron salt for the same tests. The reaction of these solids was carried out in a rotary reactor of $2.5 \mathrm{~L}$ without presence of any gas and using an apparatus of premixing step as illustrated in Figure 2. About $170 \mathrm{~g}$ of solids with a molar ratio Na/Fe close to 8 (to satisfy Equation (2)) were loaded in the reactor and rotated at a speed of $20 \mathrm{rpm}$. The premixing time was fixed at $30 \mathrm{~min}$. The evolution of temperature during the reaction was recorded and the data are displayed as plots of temperature versus time in Figure 4.

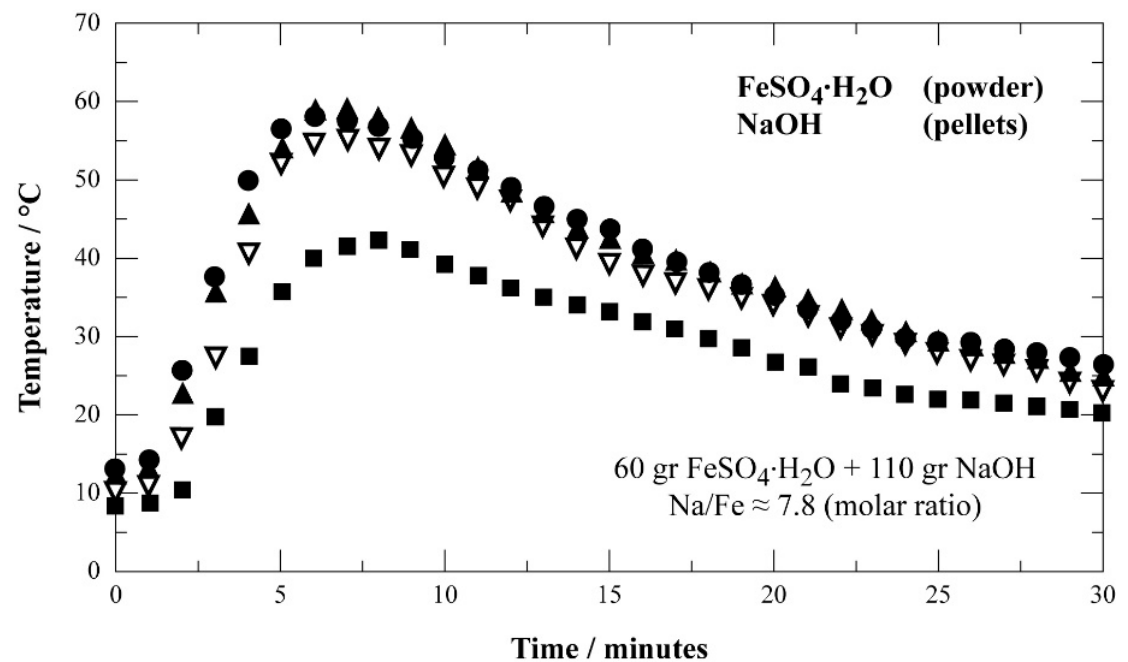

Figure 4. Evolution of the temperature as a function of time for the reaction of $\mathrm{FeSO}_{4} \cdot \mathrm{H}_{2} \mathrm{O}$ during their mixing in the rotary reactor (four trials run in same conditions).

As shown by this figure, the reaction is exothermic leading to a temperature of about $60^{\circ} \mathrm{C}$ in the reaction zone. The $\mathrm{NaOH}$ pellets become gray-black, but they more or less keep their initial shapes. Images of initial substances $\mathrm{NaOH}$ pellets (visible microscopy (VM)) and $\mathrm{FeSO}_{4} \cdot \mathrm{H}_{2} \mathrm{O}(\mathrm{SEM})$ are shown in Figure 5a,b, respectively. Figure $5 \mathrm{a}$ clearly shows that $\mathrm{NaOH}$ consists of spherical particles of a diameter lower than or equal to $2 \mathrm{~mm}$. As a contrast, $\mathrm{FeSO}_{4} \cdot \mathrm{H}_{2} \mathrm{O}$ is composed of grains of different shapes with an equivalent diameter lower than $30 \mu \mathrm{m}$ (Figure 5b).

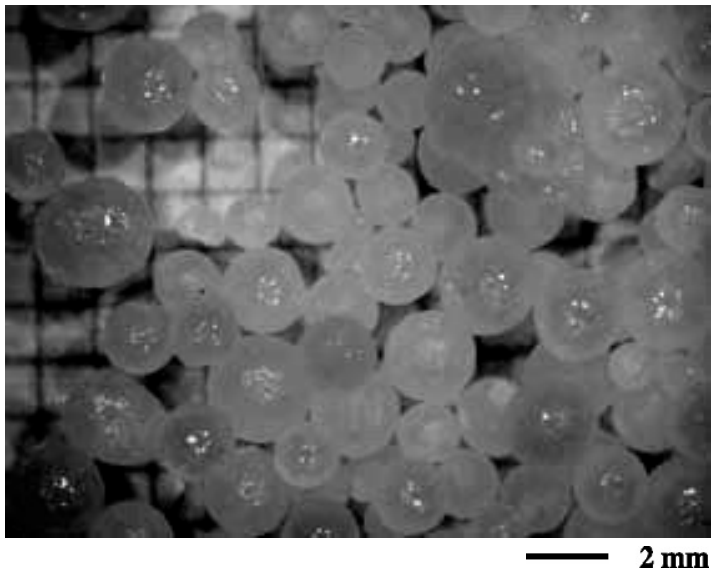

(a)

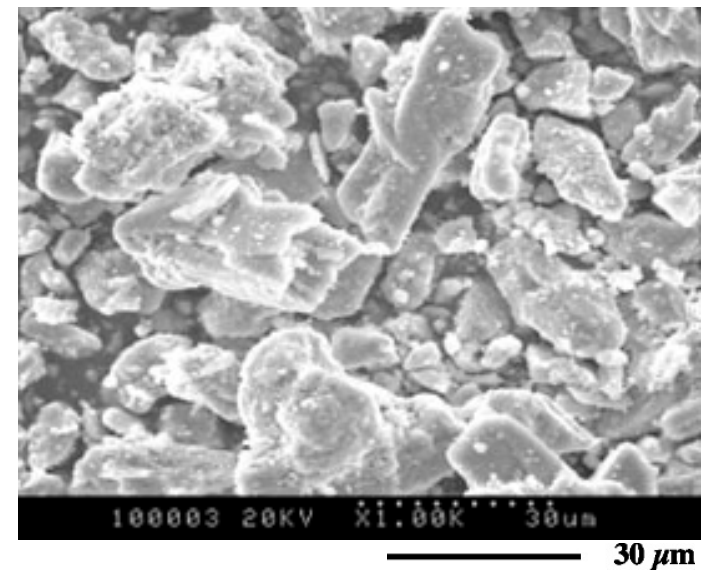

(b)

Figure 5. View of sodium hydroxide and ferrous sulfate samples: (a) Visible microscopy (VM) images of $\mathrm{NaOH}$ pellets; (b) SEM images of $\mathrm{FeSO}_{4} \cdot \mathrm{H}_{2} \mathrm{O}$. 
Some relevant information about the reaction of $\mathrm{NaOH}$ with $\mathrm{FeSO}_{4} \cdot \mathrm{H}_{2} \mathrm{O}$ was revealed by SEM-EDS investigation. A representative $\mathrm{NaOH}$ grain after reaction with iron sulfate (image SEM) and its elemental analyses (EDS) are grouped in Figure 6.
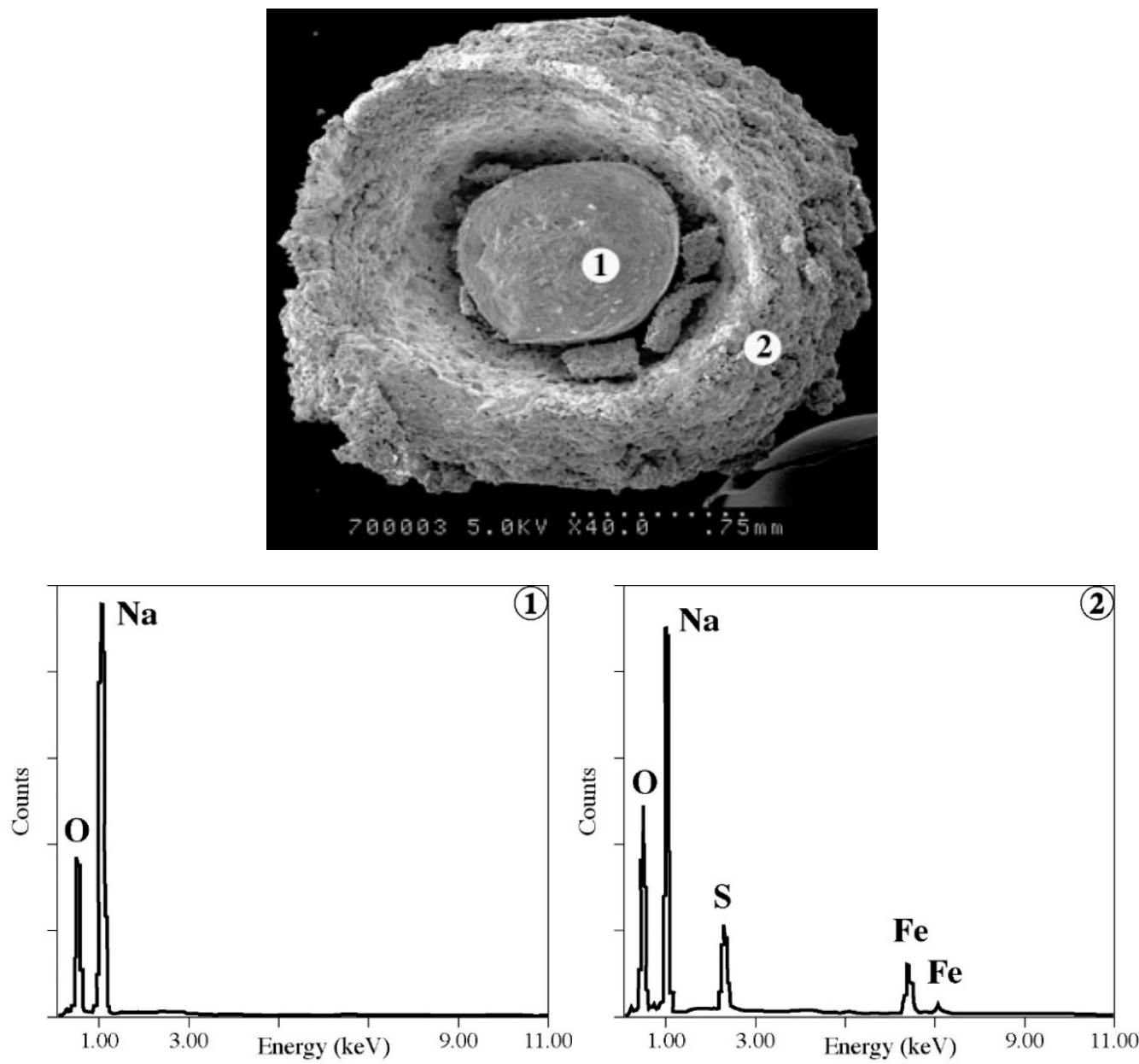

Figure 6. Scanning electron microscope coupled with energy dispersive spectrometry (SEM-EDS) examination results of a $\mathrm{NaOH}$ pellet reacted with $\mathrm{FeSO}_{4} \cdot \mathrm{H}_{2} \mathrm{O}$ : (1) core of the $\mathrm{NaOH}$ pellet; (2) outer part of the $\mathrm{NaOH}$ pellet.

The examination of these results suggests the following deductions:

- The external part of the $\mathrm{NaOH}$ pellets (spectrum 2) is essentially composed of $\mathrm{Na}, \mathrm{O}, \mathrm{S}$, and $\mathrm{Fe}$, indicating the "reaction" of $\mathrm{NaOH}$ with iron sulfate,

- The $\mathrm{NaOH}$ pellets become porous (photo of Figure 6) facilitating the diffusion of reactive gases (chlorine) during the Na-ferrate synthesis,

- The core of the pellets is composed of $\mathrm{Na}$ and $\mathrm{O}$ showing the presence of unreacted $\mathrm{NaOH}$ (note that the amount of $\mathrm{NaOH}$ was 4 times more than the stoichiometry of the reaction: $2 \mathrm{NaOH}+\mathrm{FeSO}_{4}$ $\left.\rightarrow \mathrm{Fe}(\mathrm{OH})_{2}+\mathrm{Na}_{2} \mathrm{SO}_{4}\right)$.

XRD analysis showed the presence of $\mathrm{NaOH}$ and $\mathrm{NaOH} \cdot \mathrm{H}_{2} \mathrm{O}$ as predominant crystallized phases in the mixture. The iron-bearing phase was not revealed by XRD. However, the chemical analysis of the obtained mixture indicated that this mixture contained about $93 \mathrm{~g} \mathrm{Fe} / \mathrm{kg}$ and that $54 \%$ of iron was in a three-valence state. The presence of Fe(III) was also confirmed by Mössbauer spectroscopy measurements. 
These pre-mixing materials were subjected to the Na-ferrate synthesis in a fluidized bed using diluted chlorine as an oxidation reagent.

\subsection{Preliminary Fluidization Tests of the Premixing Materials in the Fluidized Bed}

As it is well known, the fluidization of a solid by gas depends on the physical characteristics of the solid such as the density, particle size, shape, and those of the gas (gas viscosity and density).

The Reynolds $\left(R e_{M F}\right)$ and Archimedes $(A r)$ numbers as well as the minimum velocity of fluidization $\left(U_{M F}\right)$ are calculated by using the relationships available in the literature. The correlation of Wen and $\mathrm{Yu}$ [31] is used in this work, which is considered as the most known relationship related to a narrow particle size distribution. Equations (6)-(8) describe the formulas for calculating $R e_{M F}, A r$, and $U_{M F}$.

Reynolds number at minimum fluidization $\left(R e_{M F}\right)$ :

$$
\operatorname{Re}_{M F}=\left[33.7^{2}+0.0408 \frac{d_{p}^{3} \rho_{g}\left(\rho_{s}-\rho_{g}\right) g}{\mu_{g}^{2}}\right]^{1 / 2}-33.7
$$

where $\mu_{g}$ is gas viscosity $\left(\mathrm{Pa} \cdot \mathrm{s}\left(\mathrm{kg} \cdot \mathrm{s}^{-1} \cdot \mathrm{m}^{-1}\right)\right) ; \rho_{g}$ is gas density $\left(\mathrm{kg} \cdot \mathrm{m}^{-3}\right) ; \rho_{s}$ is particle density $\left(\mathrm{kg} \cdot \mathrm{m}^{-3}\right)$; $d_{p}$ is particle size $(\mathrm{m})$; and $g$ is gravitational constant $\left(\mathrm{m} \cdot \mathrm{s}^{-2}\right)$.

Archimedes number $(A r)$ :

$$
A r=\frac{d_{p}^{3} \rho_{g}\left(\rho_{s}-\rho_{g}\right) g}{\mu_{g}^{2}} .
$$

Minimum velocity of fluidization $\left(U_{M F}\right)$ :

$$
U_{M F}=R e_{M F} \frac{\mu_{g}}{d_{p} \rho_{g}}
$$

The numeric substitution of the $\left(\mu_{g}, \rho_{g}, \rho_{s}, d_{p}, g\right)$ values showed that the mean minimum velocity of the fluidization of the premixing materials is about $1 \mathrm{~m} \cdot \mathrm{s}^{-1}$. However, these values are approximate ones. For example, the solid density is considered to be $2130 \mathrm{~kg} \cdot \mathrm{m}^{-3}$ (density of $\mathrm{NaOH}$ ), but it will be less if we consider that the $\mathrm{NaOH}$ particles become porous during the reaction with iron sulfate (see photo of Figure 6).

Based on these calculations, an FB of an internal diameter of about $1.75 \mathrm{~cm}$ was designed and constructed for the synthesis of $\mathrm{Na}$-ferrate by using the $\mathrm{NaOH}$ conditioned as $2 \mathrm{~mm}$ pellets.

For the Na-ferrate synthesis, about $10 \mathrm{~g}$ of the premixed solids were loaded in the FB, creating a column of 9 to $10 \mathrm{~cm}$. A total gas flow rate of $1100 \mathrm{~L} / \mathrm{h}$ was necessary to ensure the fluidization of solids. The chlorine content of the used air $+\mathrm{Cl}_{2}$ and $\mathrm{N}_{2}+\mathrm{Cl}_{2}$ gas mixtures was kept at $5.5 \%$, whilst the synthesis time was fixed at $15 \mathrm{~min}$. The temperature of the thermostated water varied from 25 to $55^{\circ} \mathrm{C}$.

Visual observations indicated a good fluidization of the solids in FB without dust formation. This reinforces the idea that iron sulfate was well cemented during premixing $\left(\mathrm{NaOH}+\mathrm{FeSO}_{4} \cdot \mathrm{H}_{2} \mathrm{O}\right)$ in the rotary reactor. The solids after treatment in FB were examined by VM. The images of VM are compared with those of $\mathrm{NaOH}$ and premixing solids as shown in Figure 7. The results confirmed that the solids before reaction with chlorine (Figure $7 \mathrm{~b}$ ) and after (Figure 7c) had similar obvious shapes. The purple color of the solid surfaces suggested the formation of Na-ferrate. Furthermore, the dissolution in water of the solids coming from FB gave evidence of iron presence in its hexavalent state. The experimental conditions, as well as the chemical analysis of products issued from the synthesis process, are summarized in Table 1.

The synthesis products contained about 10 to $21 \mathrm{~g} / \mathrm{kg}$ of iron in a hexavalent state. The best results were obtained when nitrogen was used as diluting gas. This is probably due to the presence of moisture in the air, which can decompose the synthesized ferrate. A higher Fe(VI) yield was achieved when the water bath was regulated at $55^{\circ} \mathrm{C}$. These preliminary tests showed the possibility of the Na-ferrate synthesis in a fluidized bed using the mixture $\left(\mathrm{NaOH}+\mathrm{FeSO}_{4} \cdot \mathrm{H}_{2} \mathrm{O}\right)$ as raw materials. 
However, as the $\mathrm{NaOH}$-pellets of $2 \mathrm{~mm}$ are no longer found in the market, it is suggested to test the synthesis of Na-ferrate using $\mathrm{NaOH}$-pearls of about $1 \mathrm{~mm}(1000 \mu \mathrm{m})$.

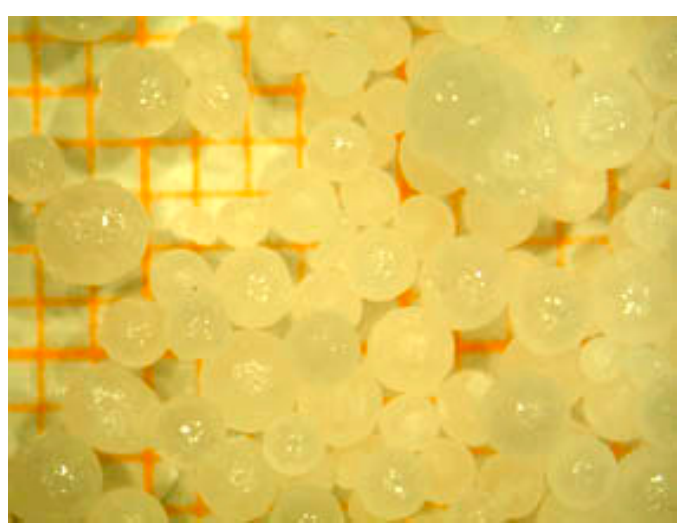

(a)

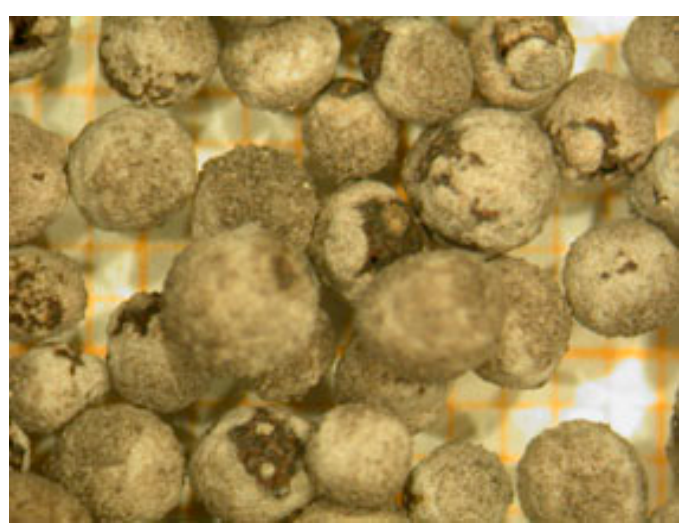

(b)

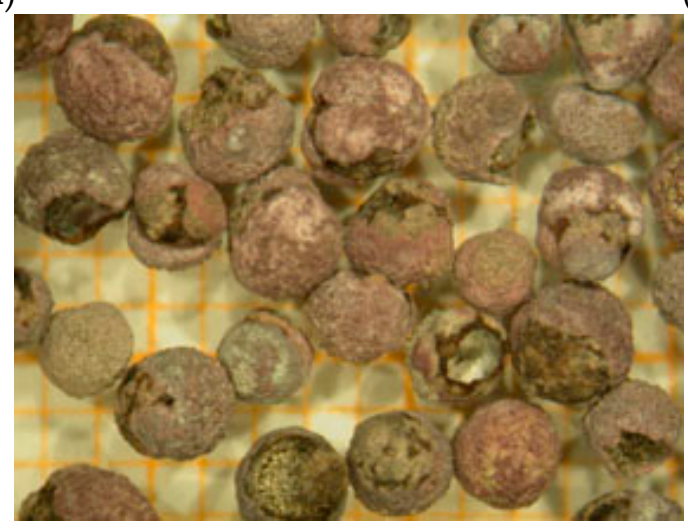

(c)

Figure 7. Visible microscopy images of $\mathrm{NaOH}$-pellets at different steps of the process (the small graduation of the paper in the background is $1 \mathrm{~mm}$ large). (a) Initial state of $\mathrm{NaOH}$; (b) $\mathrm{NaOH}+$ $\mathrm{FeSO}_{4} \cdot \mathrm{H}_{2} \mathrm{O}$ (premixing); (c) $\mathrm{NaOH}+\mathrm{FeSO}_{4} \cdot \mathrm{H}_{2} \mathrm{O}+\mathrm{Cl}_{2}$ (fluidized bed).

Table 1. Experimental conditions and Fe(VI) efficiency of synthesis using $\mathrm{NaOH}$ pellets of $2 \mathrm{~mm}$.

\begin{tabular}{ccccccc}
\hline \multicolumn{2}{c}{ Gas Mixture, Flow Rate } & $\mathbf{C l}_{\mathbf{2}} \mathbf{( \% )}$ & $\mathbf{T}\left({ }^{\circ} \mathbf{C}\right)$ & $\mathbf{t}(\mathbf{m i n})$ & $\mathbf{F e}(\mathrm{VI})(\mathrm{g} / \mathbf{k g})$ & $\mathbf{F e}(\mathrm{VI})(\mathbf{\%})$ \\
\hline \multirow{2}{*}{ Air $+\mathrm{Cl}_{2}, \mathrm{~L} / \mathrm{h}$} & 1100 & $\approx 5.5$ & 25 & 15 & 14.8 & 20.1 \\
& 1100 & $\approx 5.5$ & 35 & 15 & 15.8 & 21.2 \\
\hline & 1100 & $\approx 5.5$ & 25 & 15 & 9.8 & 12.7 \\
$\mathrm{~N}_{2}+\mathrm{Cl}_{2}, \mathrm{~L} / \mathrm{h}$ & 1100 & $\approx 5.5$ & 35 & 15 & 14.4 & 17.6 \\
& 1100 & $\approx 5.5$ & 45 & 15 & 18.4 & 22.8 \\
& 1100 & $\approx 5.5$ & 55 & 15 & 21.1 & 28.8 \\
\hline
\end{tabular}

\subsection{Premixing of $\mathrm{NaOH}$ Pearls $(1000 \mu \mathrm{m})$ with Iron Sulfate}

The tests carried out with pearls of sodium hydroxide and monohydrated ferrous sulfate in a reactor of $2.5 \mathrm{~L}$ (see Figure 2) showed that these reagents did not react like the $\mathrm{NaOH}$ pellets of $2 \mathrm{~mm}$. Therefore, it was suggested to add $\mathrm{FeSO}_{4} \cdot 7 \mathrm{H}_{2} \mathrm{O}$ in order to initiate the reaction. One may note that the particle size of $\mathrm{FeSO}_{4} \cdot 7 \mathrm{H}_{2} \mathrm{O}$ is about $0.7 \mathrm{~mm}$.

Figure 8 is a typical example of measured temperatures versus time in case of using ferrous sulfate with 3.5 and $4 \mathrm{~mol}$ of water (mixture of $\mathrm{FeSO}_{4} \cdot 7 \mathrm{H}_{2} \mathrm{O}$ and $\mathrm{FeSO}_{4} \cdot \mathrm{H}_{2} \mathrm{O}$ ). 


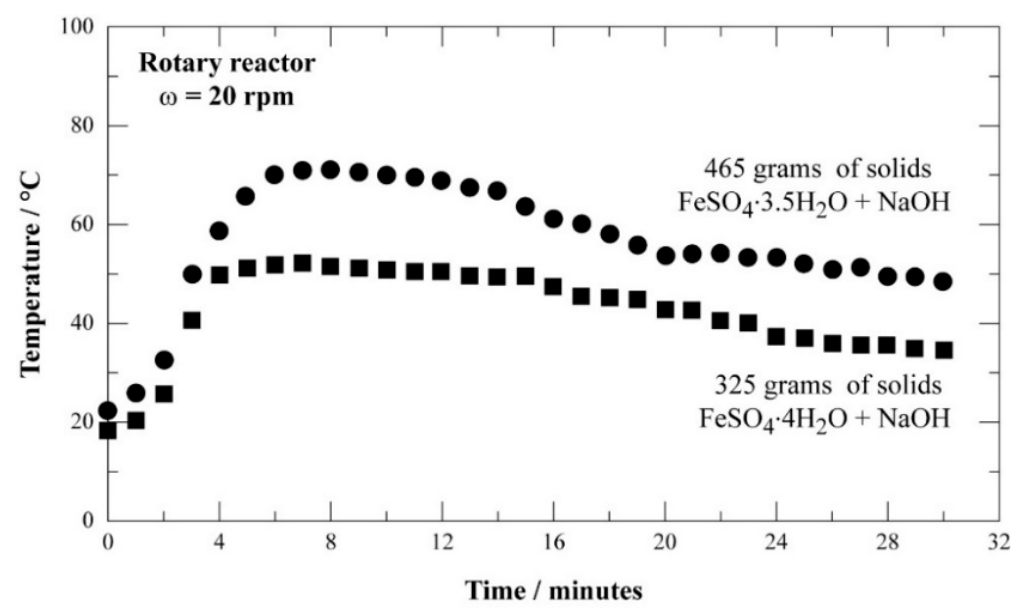

Figure 8. Evolution of the temperature as a function of time during the mixing of $\mathrm{NaOH}$ with iron sulfate $(\approx 0.7 \mathrm{~mm})$ containing 3.5 and $4 \mathrm{~mol}$ of water.

The molar ratio $\mathrm{Na} / \mathrm{Fe}$ was fixed at 8 (to satisfy Equation (2) for the subsequent ferrate synthesis). This figure indicates that it was possible to mix about 325 and $465 \mathrm{~g}$ by using a hydration degree of 4 and $3.5 \mathrm{~mol}$ for the iron sulfate, respectively. The maximum temperature in the reactor did not exceed $80^{\circ} \mathrm{C}$. However, a close examination of the obtained mixture revealed that iron sulfate heptahydrate had not fully reacted with $\mathrm{NaOH}$. This situation is presented in Figure 9 (visible microscope). Figure 9a showed the initial state of $\mathrm{NaOH}$ pearls, while Figure $9 \mathrm{~b}$ represents the $\mathrm{VM}$ view of the mixture. As shown by Figure $9 b$, a large amount of $\mathrm{FeSO}_{4} \cdot 7 \mathrm{H}_{2} \mathrm{O}$ is oxidized, agglomerated, and was difficult to separate by sieving.
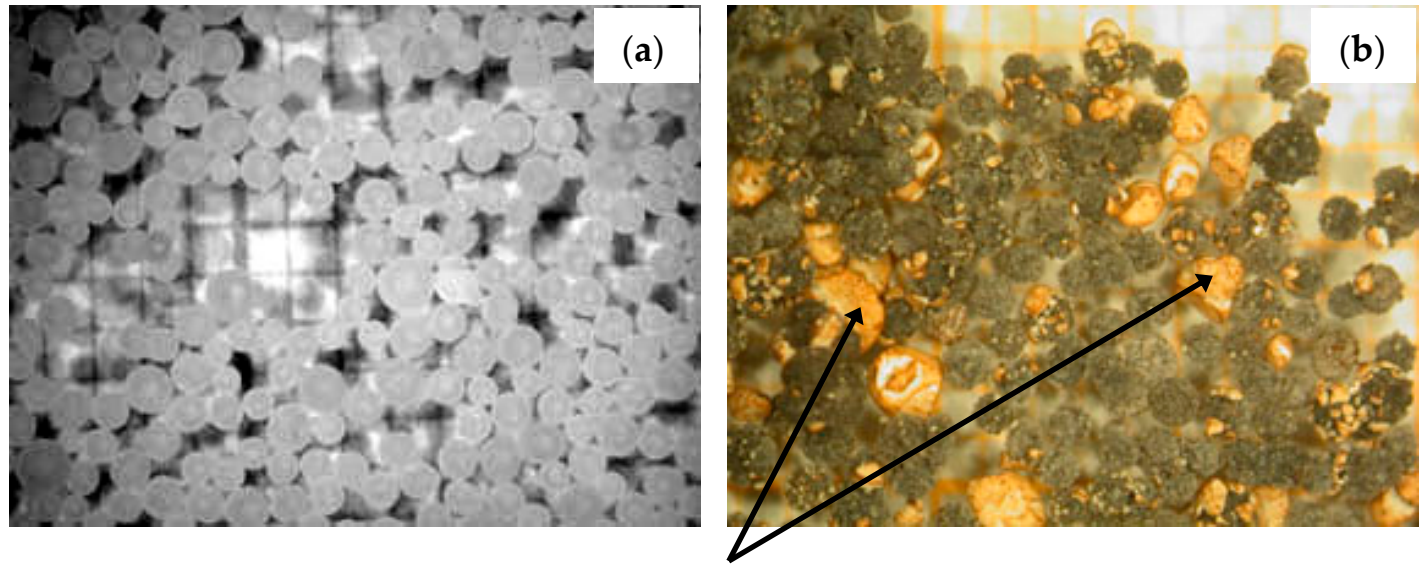

Iron sulfate oxidized and difficult to be separated

Figure 9. Visible microscopy images of sodium hydroxide (pearls-1 mm): (a) Initial state; (b) after reaction with $\mathrm{FeSO}_{4} \cdot 4 \mathrm{H}_{2} \mathrm{O}(\approx 0.7 \mathrm{~mm})$.

To overcome the phenomenon observed above, it was planned to use iron sulfate heptahydrate in powder form. The use of $0.12 \mathrm{~mol} \mathrm{FeSO}_{4} \cdot 7 \mathrm{H}_{2} \mathrm{O}$ in powder form, $0.88 \mathrm{~mol} \mathrm{FeSO}_{4} \cdot \mathrm{H}_{2} \mathrm{O}$, and $8 \mathrm{~mol} \mathrm{NaOH}$ provided the best results for obtaining the mixture $\left(\mathrm{NaOH}+\mathrm{FeSO}_{4} \cdot 7 \mathrm{H}_{2} \mathrm{O}+\mathrm{FeSO}_{4} \cdot \mathrm{H}_{2} \mathrm{O}\right)$. The results of several solid premixing tests are plotted in Figure 10, as the evolution of reactor temperature against reaction time in the case where about of $500 \mathrm{~g}$ of solids are used. As it could be expected, the reaction was exothermic, and the maximum temperature oscillated between 80 and $100^{\circ} \mathrm{C}$. The output mixture was sieved at $+850 \mu \mathrm{m}$ and was used for the synthesis of Na-ferrate in a fluidized bed. 


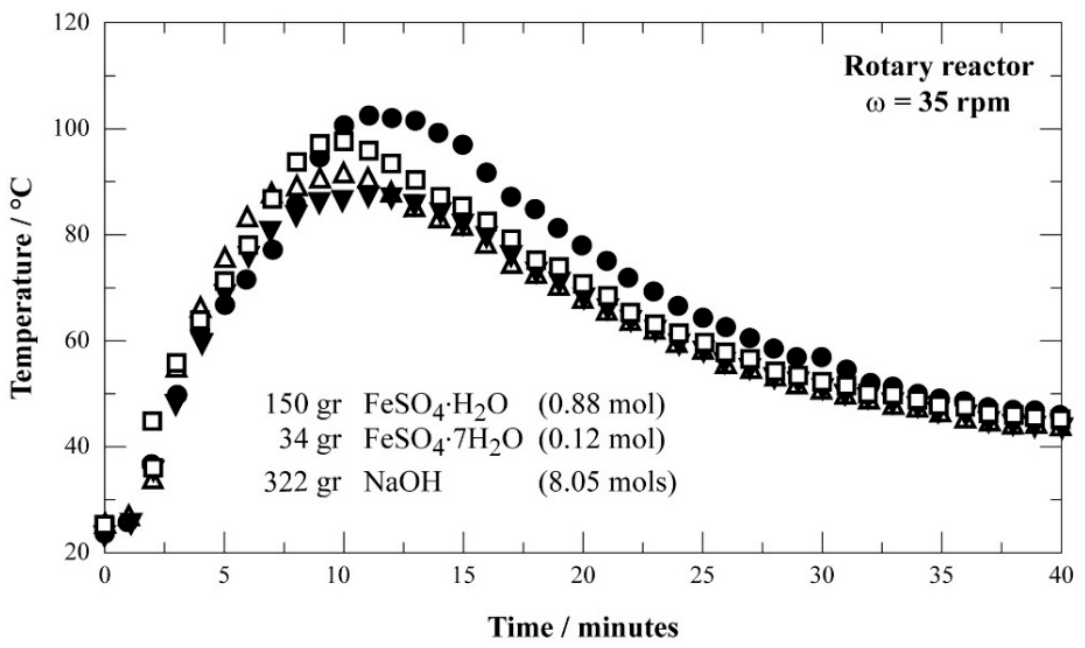

Figure 10. Evolution of the temperature as a function of time during mixing of $\mathrm{NaOH}$ with iron sulfate (powder) containing about $1.74 \mathrm{~mol}$ of water (four trials run in same conditions).

Figure 11a,b compares the VM images of the initial state of $\mathrm{NaOH}$ pearls and that of the obtained mixture according to trials mentioned above. The obtained mixture had a morphology similar to the initial $\mathrm{NaOH}$ particles.

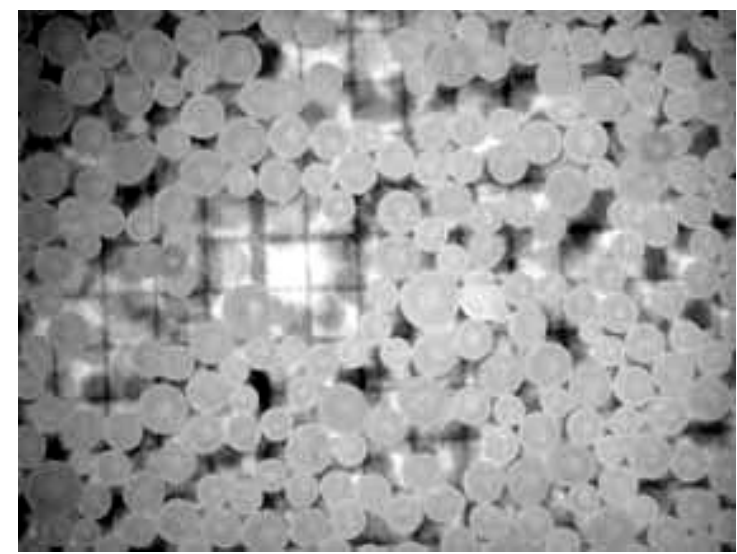

(a)

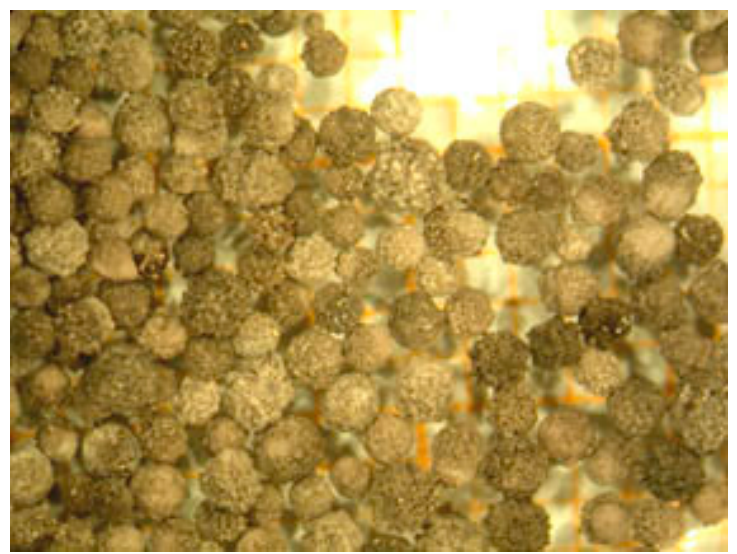

(b)

Figure 11. VM views of sodium hydroxide at: (a) Initial state, $\leq 1 \mathrm{~mm}$; (b) After reacting with powder iron sulfate.

\subsection{Synthesis of Na-Ferrate in Various Fluidized Beds}

A fluidized bed with a cross section of about $7.07 \mathrm{~cm}^{2}(\varnothing=3 \mathrm{~cm})$ was used for the synthesis of Na-ferrate based on the $\mathrm{NaOH}$-pearls mixed previously with iron sulfate. It was interesting to follow the evolution of the temperature inside the fluidized bed as the reaction progressed; this was performed by placing a thermocouple in the fluidized bed and recording the temperature.

About $10 \mathrm{~g}$ of prepared mixture were loaded in the FB. Tests were performed at regulated water temperatures varying from $20^{\circ} \mathrm{C}$ to $65^{\circ} \mathrm{C}$. The total flow rate of $\left(\right.$ air $\left.+\mathrm{Cl}_{2}\right)$ and $\left(\mathrm{N}_{2}+\mathrm{Cl}_{2}\right)$ gaseous mixture was $1800 \mathrm{~L} / \mathrm{h}$ corresponding to the operational fluidization velocity for the particles in the $\mathrm{FB}$ of $\varnothing 3 \mathrm{~cm}$. The data obtained for a water temperature set at $35^{\circ} \mathrm{C}$ are plotted in Figure $12 \mathrm{a}, \mathrm{b}$ when air $+\mathrm{Cl}_{2}$ and $\mathrm{N}_{2}+\mathrm{Cl}_{2}$ are used, respectively. The chlorine contents of both gaseous mixtures were fixed at $0.6 \%$ and $2.2 \% \mathrm{Cl}_{2}$. 

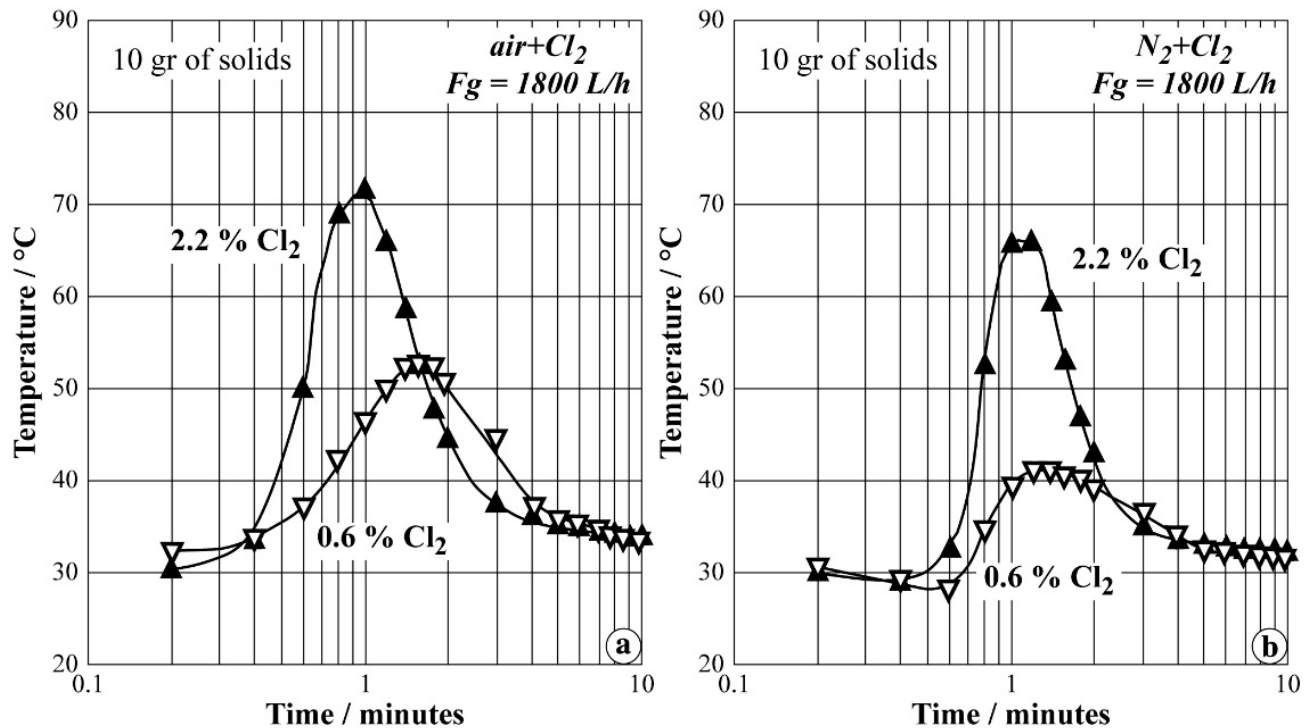

Figure 12. Plots of temperature evolution versus time during the synthesis of Na-ferrate in $\mathrm{FB}(\varnothing 3 \mathrm{~cm})$ at $35^{\circ} \mathrm{C}$ for: (a) air $+\mathrm{Cl}_{2} ;(\mathbf{b}) \mathrm{N}_{2}+\mathrm{Cl}_{2}$.

These figures clearly show that the temperature inside the FB increased sharply during the first minute of treatment. Use of $2.2 \% \mathrm{Cl}_{2}$ led to a higher maximum temperature level in both cases. The maximum temperatures observed were slightly lower when nitrogen was used instead of air. These observations are also valid over a water temperature range between $20^{\circ} \mathrm{C}$ and $65^{\circ} \mathrm{C}$. The obtained products from these tests were examined by dissolving them in water. It was observed that most of the synthesized product did not show evidence of ferrate presence in the product. Data analyses suggested that the partial pressure of chlorine in the system was too low, making the oxidation of iron at high valence impossible. In order to have the flexibility of supplying high chlorine partial pressure, it was suggested to use a fluidized bed with a smaller diameter.

Tests in the FB with $\varnothing 2 \mathrm{~cm}$ were carried out in a similar procedure as described for the previous case scenario. The total gas flow rate was $800 \mathrm{~L} / \mathrm{h}$ corresponding to the operational fluidization velocity as in the case of $\mathrm{FB}$ with $\varnothing 3 \mathrm{~cm}$. The regulation temperature of water was varied from $18{ }^{\circ} \mathrm{C}$ to $55^{\circ} \mathrm{C}$, while the chlorine content was fixed at $2.5 \%$ and $5.0 \%$. The evolution of the temperature as a function of the reaction time had a shape similar to that observed with $\mathrm{FB} \varnothing 3 \mathrm{~cm}$.

The visual tests in water for the obtained product indicated that all the synthesis products at $2.5 \%$ chlorine were characterized by the absence of Na-ferrate. As a contrast, the synthesis products at $5.0 \%$ chlorine and the water regulated temperature higher than $18{ }^{\circ} \mathrm{C}$ showed some evidences of the presence of Na-ferrate. These results confirmed that the Na-ferrate synthesis is strongly affected by chlorine partial pressure.

Several synthesis products were subjected to a chemical analysis to determine the content in total iron and $\mathrm{Fe}(\mathrm{VI})$. A summary of the experimental conditions of the Na-ferrate synthesis in $\mathrm{FB}$ of $\varnothing 2 \mathrm{~cm}$ and chemical analyses results is given in Table 2 . These results indicated that the synthesis product (after 5 min of synthesis) contained between 72 and $74 \mathrm{~g} / \mathrm{kg}$ of iron with about one half of iron as $\mathrm{Fe}(\mathrm{VI})$. Furthermore, the use of air instead of nitrogen decreased slightly the Fe(VI) efficiency.

Table 2. Experimental conditions and Fe(VI) efficiency of synthesis in FB of $\varnothing=2 \mathrm{~cm}$.

\begin{tabular}{ccccccc}
\hline \multicolumn{2}{c}{ Gas Mixture, Flow Rate } & $\mathbf{C l}_{\mathbf{2}} \mathbf{( \% )}$ & $\mathbf{T}\left({ }^{\circ} \mathbf{C}\right)$ & $\mathbf{t}(\mathbf{m i n})$ & $\mathbf{F e}(\mathrm{VI})(\mathbf{g} / \mathbf{k g})$ & $\mathbf{F e}(\mathbf{V I})(\%)$ \\
\hline \multirow{2}{*}{ Air $+\mathrm{Cl}_{2}, \mathrm{~L} / \mathrm{h}$} & 800 & $\approx 5.0$ & 40 & 5 & 36.2 & 49.3 \\
& 800 & $\approx 5.0$ & 50 & 5 & 36.8 & 50.3 \\
\hline \multirow{2}{*}{$\mathrm{N}_{2}+\mathrm{Cl}_{2}, \mathrm{~L} / \mathrm{h}$} & 800 & $\approx 5.0$ & 40 & 5 & 39.7 & 55.5 \\
& 800 & $\approx 5.0$ & 50 & 5 & 37.5 & 51.0 \\
\hline
\end{tabular}


Although the obtained results for the Na-ferrate synthesis efficiency were improved in the smallest fluidized bed $(\varnothing=2 \mathrm{~cm})$, it was observed that the fluidization regime was better in the FB of $\varnothing=3 \mathrm{~cm}$. For this reason, the fluidized bed of intermediate diameter $(\varnothing=2.5 \mathrm{~cm})$ was also checked. The experimental procedures of the corresponding tests are similar to those developed for the FB of 3 and $2 \mathrm{~cm}$.

Several experimental results are presented in Figure 13a-d plotted as the evolution of temperature inside the fluidized bed versus the reaction time in a half-logarithm scale. As in the previous case, the synthesis process seems to be completed in $5 \mathrm{~min}$.
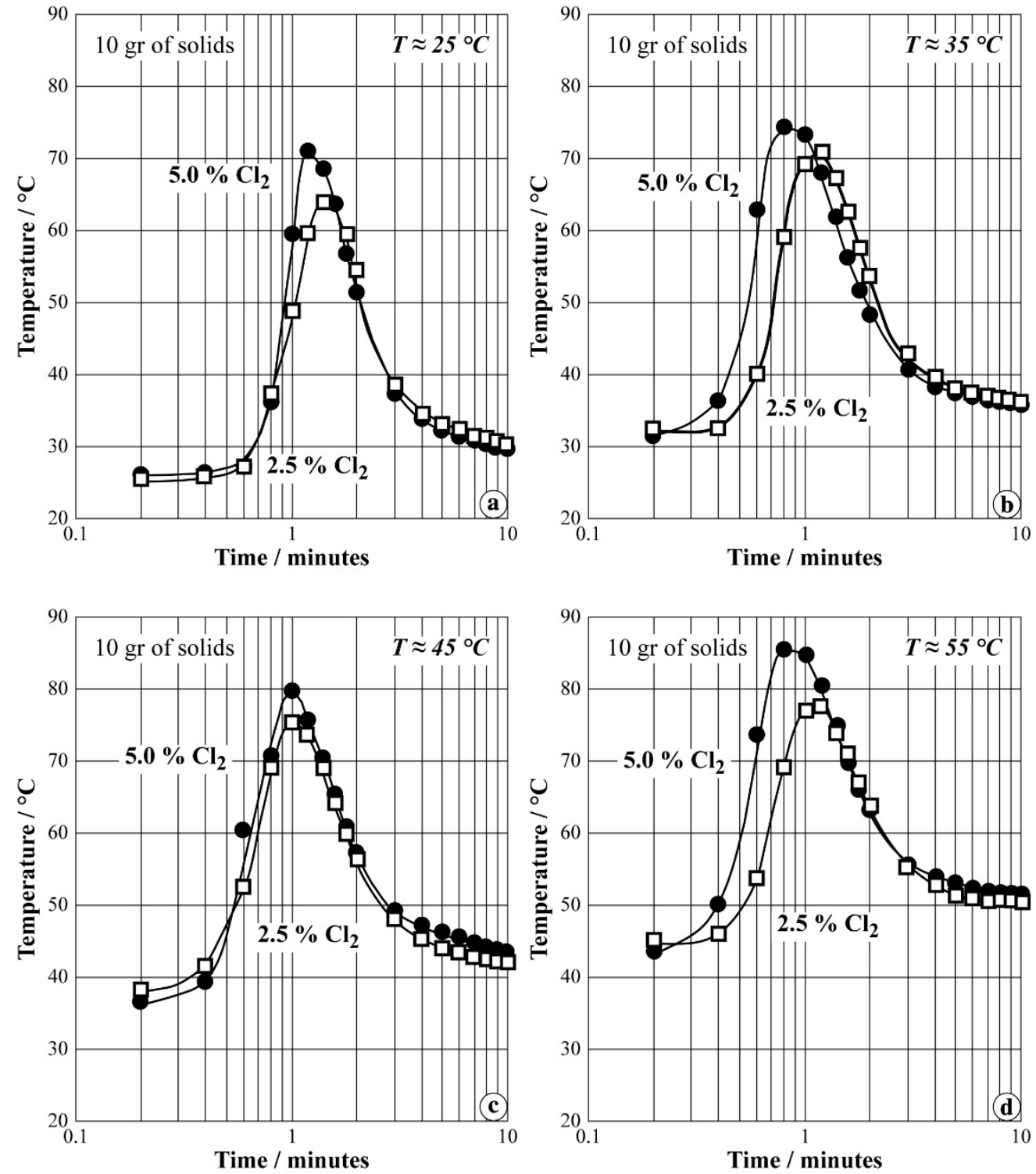

Figure 13. Plots of temperature evolution versus time during synthesis of Na-ferrate in $\mathrm{FB}(2.5 \mathrm{~cm})$ using air $+\mathrm{Cl}_{2}$ for regulated water temperature at: (a) $25^{\circ} \mathrm{C}$; (b) $35^{\circ} \mathrm{C}$; (c) $45^{\circ} \mathrm{C}$; (d) $55^{\circ} \mathrm{C}$.

Table 3 groups the experimental conditions and chemical analysis for three chosen tests of the whole series of experiments performed with FB of $\varnothing=2.5 \mathrm{~cm}$. The iron content of the synthesis process is about $75 \mathrm{~g} / \mathrm{kg}$, while the Fe(VI) yield varied between $43 \%$ and $54 \%$. It seems that the Fe(VI) synthesis efficiency decreased when the regulated temperature exceeded $40{ }^{\circ} \mathrm{C}$. The fluidization regime in $\mathrm{FB}$ of $\varnothing=2.5 \mathrm{~cm}$ is better (more homogenous) than in the case of $\varnothing=2 \mathrm{~cm}$. 
Table 3. Experimental conditions and Fe(VI) efficiency of synthesis in FB of $\varnothing=2.5 \mathrm{~cm}$.

\begin{tabular}{ccccccc}
\hline $\mathbf{N}_{\mathbf{2}}+\mathbf{C l}_{\mathbf{2}} \mathbf{( L / h )}$ & $\mathbf{C l}_{\mathbf{2}}(\mathbf{\%})$ & $\mathbf{T}\left({ }^{\circ} \mathbf{C}\right)$ & $\mathbf{t}(\mathbf{m i n})$ & $\mathbf{F e}_{\text {Total }}(\mathbf{g} / \mathbf{k g})$ & $\mathbf{F e}(\mathrm{VI})(\mathrm{g} / \mathbf{k g})$ & $\mathbf{F e}(\mathrm{VI})(\%)$ \\
\hline 1200 & $\approx 5.0$ & 30 & 5 & 74.6 & 40.1 & 53.8 \\
1200 & $\approx 5.0$ & 40 & 5 & 74.7 & 39.6 & 53.0 \\
1200 & $\approx 5.0$ & 50 & 5 & 74.4 & 31.9 & 42.9 \\
\hline
\end{tabular}

\subsection{Recycling of Non-Reacted Chlorine}

In optimum conditions of the fluidized bed tests, the content of chlorine in the gaseous mixtures (air $+\mathrm{Cl}_{2}$ and/or $\mathrm{N}_{2}+\mathrm{Cl}_{2}$ ) was kept at $5 \%$. As could be expected, only a certain fraction of chlorine is used for the ferrate synthesis. A part of unreacted chlorine was released through off-gases. Attempts were made to recycle this non-reacted chlorine. This was realized by connecting two fluidized beds in series. The off-gases of the first fluidized bed are used to supply the second FB.

About $10 \mathrm{~g}$ of the premixing material (single solid) were loaded in each FB. Gas mixture of $\mathrm{N}_{2}+\mathrm{Cl}_{2}$ $\left(5 \% \mathrm{Cl}_{2}\right)$, which was introduced in the first $\mathrm{FB}$, also passed through the second FB. A good fluidization of the first FB was observed, while the fluidization of second FB was more difficult, and the material showed a tendency to agglomerate. This is due to the water released during the ferrate synthesis in the first FB and causing a material agglomeration in the second FB. Therefore, it was suggested that the non-reacted chlorine can be recycled after a drying process to eliminate any trace of humidity. This can be easily achieved on an industrial scale, guaranteeing that no gaseous effluent is generated during the ferrate synthesis through the proposed process.

\subsection{Environmental Considerations of the Process}

Although this research is devoted to the preparation of alkali metal ferrates(VI) at room temperature, only some selected literature reports [32-43] prove the attractive properties of $\mathrm{Fe}(\mathrm{VI})$ for different end-use applications. Adjectives such as "environmentally friendly oxidant", "green oxidant", "strong oxidant", "powerful oxidant", and "super-iron battery" are often reserved for this class of materials.

The synthesis of ferrates, as described by this process, should be considered as a "green chemistry" process. The following paragraphs list some supporting evidence of this by comparing the principles of green chemistry [44] with our suggested process.

- Atom economy - synthetic methods should be designed to maximize the incorporation of all materials used in the process into the final product (almost all materials used are found in the final synthesis product);

- Safer solvents and auxiliaries - the use of auxiliary substances should be made unnecessary wherever possible and innocuous when used (no solvent or auxiliary substances-separation agents-are used for the ferrate synthesis by the proposed process);

- Design for energy efficiency - if possible, synthetic methods should be conducted at ambient temperature and pressure (it is exactly the case of the ferrate synthesis by the proposed process);

- Use of renewable feedstocks - a raw material or feedstock should be renewable rather than depleting whenever technically and economically practicable (raw materials used for the ferrate synthesis, i.e., $\mathrm{Cl}_{2}$ and $\mathrm{NaOH}$ supply, is considered as almost as non-depletable);

- Design for degradation-chemical products should be designed so that at the end of their function, they break down into innocuous degradation products and do not persist in the environment (ferrates are transformed during their usage into hydroxides and/or oxides of Fe(III), considered as environmentally friendly compounds). 


\section{Conclusions}

In this research, the possibility of transforming an industrial waste into supper-oxidizing materials (alkali metal ferrates) containing iron in its hexavalent state is shown. The following conclusions may be drawn from this investigation:

The proposed process for the synthesis of alkali ferrates included two main steps: (i) Premixing of $\mathrm{NaOH}$ with iron sulfate (solid-solid reactions) leading to a single solid, and (ii) fluidization of the obtained mixture in diluted chlorine (gas-solid reactions).

The premixing of the solids was achieved in a rotary reactor and the overall reaction was exothermic. The number of solids, the $\mathrm{NaOH}$ particle size, the $\mathrm{Na} / \mathrm{Fe}$ ratio, and the moisture of the input materials $\left(\mathrm{FeSO}_{4} \cdot \mathrm{H}_{2} \mathrm{O}\right.$ and/or $\left.\mathrm{FeSO}_{4} \cdot 7 \mathrm{H}_{2} \mathrm{O}\right)$ affected this step. Temperatures lower than $100{ }^{\circ} \mathrm{C}$ were required to obtain good results for the premixing.

The output materials of the premixing, a single solid, contains about 80 to $90 \mathrm{~g}$ of Fe/ $/ \mathrm{kg}$ of iron depending on the experimental conditions. Both Fe(II) and Fe(III) are present in the obtained mixture.

Various fluidized beds (with different cross sections) were designed and tested for the fluidization of the already prepared mixture. The fluidization was realized by air $+\mathrm{Cl}_{2}$ and/or $\mathrm{N}_{2}+\mathrm{Cl}_{2}$ assuring operational fluidization velocities.

The synthesis tests are carried out by varying parameters such as temperature of the thermostated water, partial pressure of chlorine, type of $\mathrm{NaOH}$ (2-mm pellets and 1-mm pearls), reaction time, etc.

The results suggest that fluidization is easy to achieve and that almost no dust is generated during the Na-ferrate synthesis in the fluidized bed, indicating that the iron sulfate is well embedded in the $\mathrm{NaOH}$ grains during the premixing step. The synthesis process is exothermic, and it is completed within a few minutes. Heat and water are rapidly evacuated from the reaction zone, leading to a dried Na-ferrate. This is a substantial advantage of performing the ferrate synthesis in a fluidized bed.

It seems that temperatures regulated close to $30^{\circ} \mathrm{C}$ and temperatures in the fluidized bed lower than or equal to $70{ }^{\circ} \mathrm{C}$ (due to the exothermic reactions) provide the best results for the Na-ferrate synthesis. The Fe(VI) synthesis efficiency varied between $30 \%$ and $55 \%$ depending on other experimental parameters.

Ferrates obtained by this process could be used directly for different applications without any additional preliminary treatment (such as crushing), keeping in mind that the mean particle size of the ferrate produced by this invented process is close to $1 \mathrm{~mm}$.

The proposed synthesis process meets numerous green chemistry and sustainable development principles. The synthesis product, alkali metal ferrates(VI), belongs to an advanced materials category with multipurpose functions for water and wastewater treatment as well as for cleaning various industrial effluents.

\section{Patents}

Kanari, N. Method of producing ferrates(VI). French patent, publication date: 14 March 2008, no. 2905 609. Extension at international level: 13 March 2008, no. WO 2008/029046.

Author Contributions: Conceptualization, N.K.; formal analysis, C.D., I.F., S.S. and F.D.; investigation, N.K., E.O., C.D. and F.D.; visualization, E.O., I.F., S.S. and F.D.; resources, N.K., C.D. and J.Y.; writing-original draft, N.K., E.O., E.A. and F.P.; writing-review and editing, N.K., E.A., F.P. and J.Y.

Funding: A significant amount of this work is performed in the frame of contract no. G5RD-CT-2001-03011 (FP5-GROWTH) of the European Union. Further developments of the work have been supported by ANR program "Investissements d'avenir" - ANR-10-LABX-21-01/LABEX RESSOURCES21.

Conflicts of Interest: The authors declare no conflict of interest.

\section{References}

1. Kanari, N.; Menad, N.-E.; Ostrosi, E.; Shallari, S.; Diot, F.; Allain, E.; Yvon, J. Thermal behavior of hydrated iron sulfate in various atmospheres. Metals 2018, 8, 1084. [CrossRef] 
2. Kanari, N.; Filippova, I.; Diot, F.; Mochón, J.; Ruiz-Bustinza, I.; Allain, E.; Yvon, J. Utilization of a waste from titanium oxide industry for the synthesis of sodium ferrate by gas-solid reactions. Thermochim. Acta 2014, 575, 219-225. [CrossRef]

3. Council Directive 92/112/EEC of 15 December 1992 on Procedures for Harmonizing the Programmes for the Reduction and Eventual Elimination of Pollution Caused by Waste from the Titanium Dioxide Industry. Available online: https://eur-lex.europa.eu/legal-content/EN/TXT/?uri=CELEX\%3A31992L0112 (accessed on 18 May 2019).

4. Gázquez, M.J.; Bolívar, J.P.; García-Tenorio, R.; Vaca, F. Physicochemical characterization of raw materials and co-products from the titanium dioxide industry. J. Hazard. Mater. 2009, 166, 1429-1440. [CrossRef] [PubMed]

5. Li, X.; Lei, Z.; Qu, J.; Li, Z.; Zhou, X.; Zhang, Q. Synthesizing slow-release fertilizers via mechanochemical processing for potentially recycling the waste ferrous sulfate from titanium dioxide production. J. Environ. Manag. 2017, 186, 120-126. [CrossRef] [PubMed]

6. Wu, L.; Wang, Z.; Li, X.; Guo, H.; Li, L.; Wang, X.; Zheng, J. Cation-substituted $\mathrm{LiFePO}_{4}$ prepared from the $\mathrm{FeSO}_{4} \cdot 7 \mathrm{H}_{2} \mathrm{O}$ waste slag as a potential Li battery cathode material. J. Alloys Compd. 2010, 497, 278-284. [CrossRef]

7. Huang, P.; Deng, S.; Zhang, Z.; Wang, X.; Chen, X.; Yang, X.; Yang, L. A sustainable process to utilize ferrous sulfate waste from titanium oxide industry by reductive decomposition reaction with pyrite. Thermochim. Acta 2015, 620, 18-27. [CrossRef]

8. Kanari, N.; Evrard, O.; Neveux, N.; Ninane, L. Recycling ferrous sulfate via super-oxidant synthesis. JOM 2001, 53, 32-33. [CrossRef]

9. Kanari, N.; Ostrosi, E.; Ninane, L.; Neveux, N.; Evrard, O. Synthesizing alkali ferrates using a waste as a raw material. JOM 2005, 57, 39-42. [CrossRef]

10. Kanari, N.; Filippov, L.; Diot, F.; Mochón, J.; Ruiz-Bustinza, I.; Allain, E.; Yvon, J. Synthesis of potassium ferrate using residual ferrous sulfate as iron bearing material. J. Phys. Conf. Ser. 2013, 416, 012013. [CrossRef]

11. Fremy, E. Recherches sur l'action des peroxides alcalins sur les oxides métalliques: Lettre de M. Ed. Fremy à M. Pelouze. Comptes Rendus de l'Académie des Sci. Paris 1841, 12, 23-24.

12. Fremy, E. Recherches sur les acides métalliques. Comptes Rendus de l'Académie des Sci Paris 1842, 14, 442-446.

13. Fremy, E. Recherches sur les acides métalliques. Annales de Chimie et de Phys. 1844, 361-382.

14. Whal, K.; Klemm, W.; Wehrmeyer, G. Über einige oxokomplexe von übergangselementen. Z. Anorg. Allg. Chem. 1956, 285, 322-336. [CrossRef]

15. Kiselev, N.S.; Kopelev, N.S.; Zavyalova, N.A.; Perfiliev, Y.D. The preparation of alkali metal ferrates(VI). Russ. J. Inorg. Chem. 1989, 34, 1250-1253.

16. Cici, M.; Cuci, Y. Production of some coagulant materials from galvanizing workshop waste. Waste Manag. 1998, 17, 407-410. [CrossRef]

17. Ockerman, L.T.; Schreyer, J.M. Preparation of sodium ferrate (VI). J. Am. Chem. Soc. 1951, 73, 5479. [CrossRef]

18. Schreyer, J.M.; Thompson, G.W.; Ockerman, L.T. Potassium ferrate (VI). Inorg. Synth. 1953, 4, $164-167$.

19. Williams, D.H.; Riley, J.T. Preparation and alcohol oxidation studies of the ferrate (VI) ion. Inorg. Chim. Acta 1974, 8, 177-183. [CrossRef]

20. Lee, Y.; Cho, M.; Kim, J.Y.; Yoon, J. Chemistry of ferrrate (Fe(VI)) in aqueous solution and its applications as a green chemical. J. Ind. Eng. Chem. 2004, 10, 161-171.

21. Licht, S.; Tel-Vered, R.; Halperin, L. Direct electrochemical preparation of solid Fe(VI) ferrate, and super-iron battery compounds. Electrochem. Commun. 2002, 4, 933-937. [CrossRef]

22. Mácová, Z.; Bouzek, K.; Híveš, J.; Sharma, V.K.; Terryn, R.J.; Baum, J.C. Research progress in the electrochemical synthesis of ferrate(VI). Electrochim. Acta 2009, 54, 2673-2683. [CrossRef]

23. Sun, X.; Zhang, Q.; Liang, H.; Ying, L.; Xiangxu, M.; Sharma, V.K. Ferrate(VI) as a greener oxidant: Electrochemical generation and treatment of phenol. J. Hazard. Mater. 2016, 319, 130-136. [CrossRef] [PubMed]

24. Kanari, N.; Allain, E.; Shallari, S.; Diot, F.; Diliberto, S.; Patisson, F.; Yvon, J. Thermochemical route for extraction and recycling of critical, strategic and high value elements from by-products and end-of-life materials, Part I: Treatment of a copper by-product in air atmosphere. Materials 2019, 12, 1625. [CrossRef] [PubMed] 
25. Jeannot, C.; Malaman, B.; Gérardin, R.; Oulladiaf, B. Synthesis, crystal and magnetic structures of the sodium ferrate (IV) $\mathrm{Na}_{4} \mathrm{FeO}_{4}$ studied by neutron diffraction and Mössbauer techniques. J. Solid State Chem. 2002, 165, 266-277. [CrossRef]

26. Kanari, N.; Allain, E.; Gaballah, I. Reactions of wüstite and hematite with different chlorinating agents. Thermochim. Acta 1999, 335, 79-86. [CrossRef]

27. Gaballah, I.; Ivanaj, S.; Kanari, N. Kinetics of chlorination and oxychlorination of chromium (III) oxide. Metall. Mat. Trans. B 1998, 29A, 1299-1308. [CrossRef]

28. Kanari, N.; Gaballah, I.; Allain, E. Kinetics of oxychlorination of chromite Part I. Effect of temperature. Thermochim. Acta 2001, 371, 143-154. [CrossRef]

29. Kanari, N.; Gaballah, I.; Allain, E. Kinetics of oxychlorination of chromite Part II. Effect of reactive gases. Thermochim. Acta 2001, 371, 75-86. [CrossRef]

30. Roine, A. Outokumpu HSC Chemistry for Windows Version 3.0; Outokumpu Research: Pori, Finland, 1997.

31. Wen, C.Y.; Yu, Y.H. A generalized method for predicting the minimum fluidization velocity. AIChE J. 1966, 12, 610-612. [CrossRef]

32. Sharma, V.K. Potassium ferrate(VI): An environmentally friendly oxidant. Adv. Environ. Res. 2002, 6, 143-156. [CrossRef]

33. Sharma, V.K. Ferrate(V) oxidation of pollutants: A premix pulse radiolysis study. Radiat. Phys. Chem. 2002, 65, 349-355. [CrossRef]

34. Ninane, L.; Kanari, N.; Criado, C.; Jeannot, C.; Evrard, O.; Neveux, N. New processes for alkali ferrate synthesis. In Ferrates: Synthesis, Properties and Applications in Water and Wastewater Treatment; Sharma, V.K., Ed.; American Chemical Society: Washington, DC, USA, 2008; pp. 102-111.

35. Jiang, J.Q. Research progress in the use of ferrate(VI) for the environmental remediation. J. Hazard. Mater. 2007, 146, 617-623. [CrossRef] [PubMed]

36. Alsheyab, M.; Jiang, J.-Q.; Stanford, C. On-line production of ferrate with an electrochemical method and its potential application for wastewater treatment-A review. J. Environ. Manag. 2009, 90, 1350-1356. [CrossRef] [PubMed]

37. Wang, Y.L.; Ye, S.H.; Wang, Y.Y.; Cao, J.S.; Wu, F. Structural and electrochemical properties of a $\mathrm{K}_{2} \mathrm{FeO}_{4}$ cathode for rechargeable Li ion batteries. Electrochim. Acta 2009, 54, 4131-4135. [CrossRef]

38. Filip, J.; Yngard, R.A.; Siskova, K.; Marusak, Z.; Ettler, V.; Sajdl, P.; Sharma, V.K.; Zboril, R. Mechanisms and efficiency of the simultaneous removal of metals and cyanides by using ferrate(VI): Crucial roles of nanocrystalline iron (III) oxyhydroxides and metal carbonates. Chem. Eur. J. 2011, 17, 10097-10105. [CrossRef]

39. Yates, B.J.; Zboril, R.; Sharma, V.K. Engineering aspects of ferrate in water and wastewater treatment-A review. J. Environ. Sci. Health Part A 2014, 49, 1603-1614. [CrossRef]

40. Jiang, Y.; Goodwill, J.E.; Tobiason, J.E.; Reckhow, D.A. Effect of different solutes, natural organic matter, and particulate $\mathrm{Fe}(\mathrm{III})$ on ferrate(VI) decomposition in aqueous solutions. Environ. Sci. Technol. 2015, 49, 2841-2848. [CrossRef]

41. Wei, Y.-L.; Wang, Y.-S.; Liu, C.-H. Preparation of potassium ferrate from spent steel pickling liquid. Metals 2015, 5, 1770-1787. [CrossRef]

42. Goodwill, J.E.; Jiang, Y.; Reckhow, D.A.; Tobiason, J.E. Laboratory assessment of ferrate for drinking water treatment. J. Am. Water Works Assoc. 2016, 108, E164-E174. [CrossRef]

43. Han, H.; Li, J.; Ge, Q.; Wang, Y.; Chen, Y.; Wang, B. Green ferrate(VI) for multiple treatments of fracturing wastewater: Demulsification, visbreaking, and chemical oxygen demand removal. Int. J. Mol. Sci. 2019, 20, 1857. [CrossRef]

44. Anastas, P.T.; Warner, J.C. Green Chemistry: Theory and Practice; Oxford University Press: New York, NY, USA, 1998 ; p. 30.

(C) 2019 by the authors. Licensee MDPI, Basel, Switzerland. This article is an open access article distributed under the terms and conditions of the Creative Commons Attribution (CC BY) license (http://creativecommons.org/licenses/by/4.0/). 